\title{
On the move: Redox -dependent protein relocation
}

2 - Christine H. Foyer ${ }^{1,2 * \#}$, Alison Baker ${ }^{1,3,4 \#}$, Megan Wright ${ }^{4,5}$, Imogen A. Sparkes ${ }^{6}$, Amna

3 Mhamdi $^{7,8}$, Jos H.M. Schippers ${ }^{9,}$ Frank Van Breusegem ${ }^{7,8}$

$4-$

5 - ${ }^{1}$ Centre for Plant Sciences, Faculty of Biological Sciences, University of Leeds, Leeds,

$6 \quad$ LS2 9JT, UK.

$7-{ }^{2}$ School of Biology, Faculty of Biological Sciences, University of Leeds, Leeds, LS2

$8 \quad 9 \mathrm{JT}, \mathrm{UK}$

$9 \quad-{ }^{3}$ School of Molecular and Cellular Biology, Faculty of Biological Sciences, University of

10 Leeds, Leeds, LS2 9JT, UK

$11-{ }^{4}$ The Astbury Centre for Structural Biology, University of Leeds, Leeds, LS2 9JT, UK

$12-{ }^{5}$ School of Chemistry, University of Leeds, Leeds, LS2 9JT, UK

$13-{ }^{6}$ School of Biological Sciences, University of Bristol, Bristol Life Sciences Building, 24

14 Tyndall Avenue, Bristol, BS8 1TQ

$15{ }^{7}$ VIB-UGent Center for Plant Systems Biology, Ghent University, Technologiepark 71 -

169052 Ghent - Belgium

$17{ }^{8}$ Department of Plant Biotechnology and Bioinformatics. Ghent University,

18 Technologiepark $71-9052$ Ghent, Belgium

$19{ }^{9}$ Institute of Biology I, RWTH Aachen University, Worringerweg 1, 52074 Aachen,

20 Germany.

22 Short title: Redox-dependent protein relocation

24 * Corresponding author: Christine H. Foyer, C.Foyer@leeds.ac.uk;

$25{ }^{\#}$ These authors have contributed equally to this work and are hence joint first authors 
27 Key words: catalase, moonlighting proteins, nitric oxide, reactive oxygen species, redox

28 signaling, stromules

30 Abbreviations: ER: endoplasmic reticulum; CAT: catalase; GAPDH: glyceraldehyde 3-

31 phosphate dehydrogenase; NPR1: NON-EXPRESSOR OF PATHOGENESIS-RELATED

32 GENES 1; PR: pathogenesis-related; PRX: peroxiredoxins; PTM: post-translational 33 modifications; ROS: reactive oxygen species; RNS: reactive nitrogen species, SA: salicylic 34 acid; SAR: systemic acquired resistance; SOD: Superoxide Dismutase; TRX: thioredoxin ;

35 UPS: Ubiquitin-proteasome system; WHY1: WHIRLY1

38 Figures: 4 plus 1in Box 1 (Figure 5)

39 Tables: 1

40 Boxes: 1 


\section{ABSTRACT}

44 Compartmentation of proteins and processes is a defining feature of eukaryotic cells. The 45 growth and development of organisms is critically dependent on the accurate sorting of 46 proteins within cells. The mechanisms by which cytosol-synthesized proteins are delivered to 47 the membranes and membrane compartments have been extensively characterised. However, 48 the protein complement of any given compartment is not precisely fixed and some proteins 49 can move between compartments in response to metabolic or environmental triggers. The 50 mechanisms and processes that mediate such relocation events are largely uncharacterized. 51 Many proteins can in addition perform multiple functions, catalyzing alternative reactions or 52 performing structural, non-enzymatic functions. These alternative functions can be equally 53 important functions in each cellular compartment. Such proteins are generally not dual 54 targeted proteins in the classic sense of having targeting sequences that direct de novo 55 synthesised proteins to specific cellular locations. Accumulating evidence suggests that redox 56 post-translational modifications (PTMs) can control the compartmentation of many such 57 proteins, including antioxidant and/or redox associated enzymes. 
59

60

61

62

\section{INTRODUCTION}

Many proteins perform multiple unrelated functions, often in different locations. These are often referred to as moonlighting proteins. Some of these proteins have been known for decades. However, the number and diversity of proteins that either can have different functions in the same intracellular compartment or that can move from one compartment to another to fulfil different functions has increased enormously in recent years, aided by development and application of bioinformatic (Chapple et al., 2015) proteomic (Thul et al., 2017) and cell imaging techniques (Chong et al., 2015; Thul et al., 2017). These reveal the extent to which proteins can show multiple subcellular localisations (up to $50 \%$ of cellular proteins), as well as how these may change in response to cellular perturbation (Chong et al., 2015), including in disease states like cancer in animals (Min et al., 2016) and stress responses in plants (Sun et al. 2018). Several metabolic enzymes are known to move into the nucleus affecting epigenetic modifications (Boukouris et al., 2016) and histone expression (He et al., 2013) providing a link between metabolism and gene expression. Whilst most studies have been conducted on yeast and mammalian cells, evidence for proteins with multiple, largely unrelated functions in plants is also incontrovertible (Table I). A recent study in Arabidopsis identified a number of metabolic enzymes as members of the RNA binding protein repertoire (Marondedze et al., 2016). Not all proteins that move moonlight, and not all proteins that moonlight move compartments to do so. For example, L-galactono-1, 4-lactone dehydrogenase has dual functions in plant mitochondria. Firstly, as an enzyme it is responsible for the synthesis of ascorbic acid, and as a chaperone it is essential for the assembly of respiratory complex I (Schimmeyer et al., 2016). Similarly plastid NAD dependent malate dehydrogenase has a non-enzymatic function stabilising the FtsH12 component of the inner envelope AAA ATPase (Schreier et al., 2018).

Regulated protein relocation provides a robust and flexible mechanism for metabolic, genetic and epigenetic regulation in response to metabolic stimuli and environmental cues. Such responses often entail shifts in cellular redox homeostasis that lead to both oxidative and reductive events that shift protein functions and compartmentation. One paradigm for such redox-related changes is NPR1, which is a master regulator of salicylic acid (SA)-mediated systemic acquired resistance (SAR) leading to broad-spectrum disease resistance in plants (Mou et al., 2003). A second paradigm is organelle-to-nucleus retrograde signalling pathways that allow cells to adapt to changes in metabolic state, often in a redox-dependent manner (Boukouris et al., 2016; Monaghan and Whitmarsh, 2015). Redox cues and associated PTMs 
92 are often fundamental regulators of alternative protein functions and localization. However,

93 the extent of this phenomenon, what makes proteins move and the mechanisms by which they

94 do so remains largely obscure.

\section{MECHANISMS OF PROTEIN MOVEMENT IN PLANTS}

96 ROS triggered post translational modifications (PTMS)

97 All cells use oxidative catabolic processes to release energy and anabolic reductive process to assimilate energy in synthetic reactions. Redox signalling was one of the first regulatory pathways to evolve to avoid "boom" and "bust" scenarios in energy availability and usage

100 (Foyer and Allen, 2003). Examples of oxidative stress triggered protein movement are 101 known in yeast (e.g. Superoxide Dismutase SOD1 (Tsang et al., 2014)) and mammalian cells 102 (e.g NRF2, CLK-1, glyceraldehyde 3-phosphate dehydrogenase (GAPDH) reviewed in (Min 103 et al., 2016; Monaghan and Whitmarsh, 2015) and results in these proteins exhibiting 104 moonlighting activity within the nucleus.

105 Reactive Oxygen Species (ROS) serve as key regulators of a diverse range of important 106 functions in plants. In particular, they serve as signalling molecules that control plant growth 107 through processes such a mitosis, cell expansion and differentiation (Mhamdi and Van 108 Breusegem, 2018). ROS are essential signals produced by cellular energy metabolism and by 109 specific enzymes such as NADPH oxidases in order to modulate redox-sensitive processes 110 (Schmidt and Schippers, 2015). Chloroplasts, mitochondria and peroxisomes are thus not 111 only the essential sites of metabolic energy production and utilization, but also important 112 sources of ROS and other redox regulators that influence nearly every aspect of cell biology 113 (Noctor and Foyer, 2016). While cells regulate redox processes in a compartment-specific 114 manner, redox PTMs may also be used to regulate the movement of proteins between 115 compartments. Moreover, proteins such as peroxiredoxins (PRX) that readily undergo redox 116 PTMS in their roles as ROS scavengers are moonlighting enzymes that have evolved to 117 support multiple functions (acting as peroxidases, signalling proteins and chaperones) under 118 optimal and stress conditions. Like other redox proteins, whose functions are supported by 119 thiol-based biochemistry, PRX can interact with multiple cellular partners in animals and 120 plants, from thioredoxins to transcription factors (Liebthal et al., 2018). They are thus a 121 paradigm for moonlighting proteins

122 Assessing the protein-protein interactions that are involved in the functions of PRXs and 123 other redox regulated proteins such as NPR1 entails considerations of the interdependent 
124 facets of redox state and oligomeric structure. Redox PTMs on protein cysteines are formed 125 non-enzymatically via promiscuous reactive species, including ROS, reactive nitrogen 126 species (RNS), and other radicals or electrophilic lipids. There is growing appreciation that 127 redox PTMs are site-specific, governed by the microenvironment of cysteine residues, and 128 subject to temporal and spatial control. Small molecule and protein-based fluorescent sensors 129 have shown that eukaryotic cells tightly control the location of reactive species, proteins and 130 redox state across compartments (Kaludercic et al., 2014), and that this balance is, for 131 example, altered during ageing in the model organism C. elegans (Kirstein et al., 2015).

132 Recent evidence suggests that ROS and redox cues modify microtubule orientation and 133 behaviour within plant cells (Dang et al., 2018), as well as the operation of protein import 134 machineries (reviewed in (Bolter et al., 2015; Ling and Jarvis, 2015). Redox PTMs not only 135 control activities and binding partners but also the compartmentation of many proteins, 136 including antioxidant and/or redox associated enzymes (Box I), as discussed in detail below.

\section{Protein Import and Export}

138 The molecular mechanisms of protein import into mitochondria, chloroplasts and 139 peroxisomes have now been established and the importance of the accuracy of these 140 processes underscored by the realization that defects result in human disease. Recent work 141 has revealed that protein import can be regulated at several levels; from modification of 142 individual precursor proteins to prevent or alter their targeting, to regulated interaction with 143 binding partners, and modification of the import apparatus by phosphorylation or 144 ubiquitination to alter its activity (Bolter et al., 2015; Harbauer et al., 2014; Ling et al., 2012)

145 (Figure 1). Such processes allow the location of proteins to change in response to changes in 146 cellular state. For example, in C. elegans the transcription factor ATF1 is imported into 147 mitochondria and degraded by a Lon protease but, when import is decreased, ATF1 relocates 148 to the nucleus and induces an unfolded protein response (Nargund et al., 2012). In mammals, 149 import of the protein catalase into the peroxisome is redox regulated and under stress 150 conditions the peroxisome import receptor PEX5, retains catalase in the cytosol (Walton et 151 al., 2017). PEX5 cycling between peroxisome and cytosol is regulated by ubiquitination of a 152 conserved Cys, and in mammalian cells reduced glutathione can deubiquitinate the receptor 153 (Grou et al., 2009). Intriguingly, an old observation that NADPH but not NADH inhibits 154 protein import hints at the importance of redox balance for protein import into plant 155 peroxisomes as well (Pool et al., 1998). Retrograde signalling from organelles to the nucleus 
156 to integrate cellular activities is well established, and modulation of chloroplast import

157 activity is important in response to biotic and abiotic stress (de Torres Zabala et al., 2015;

158 Ling and Jarvis, 2015).

159 As well as regulating the import of proteins, it has become apparent that proteins can be 160 exported from mitochondria, chloroplasts and peroxisomes as well as the endoplasmic

161 reticulum (ER) (Figure 1). Such export not only drives degradation of organellar proteins via 162 the cytosolic Ubiquitin-proteasome system (UPS), but also provides a link to organelle 163 quality control (Bragoszewski et al., 2017; Kao et al., 2018; Ling and Jarvis, 2016). While 164 the release of transcription factors from cellular membranes by regulated proteolysis is a 165 well-known response to stress in both animals and plants (Seo et al., 2008; Sun et al., 2011), 166 potentially, protein export and retargeting could also provide a means of signalling and 167 genetic regulation. To date this has only been proposed/described for a handful of proteins 168 and the mechanism(s) by which this occurs and is regulated are still obscure (Foyer et al., 169 2014).

171 Candidates as a paradigm for redox regulated movement in plants

172 NPR1 and ROXY proteins. NPR1 shares structural and functional characteristics with 173 mammalian immune co-factor I k B and the transcription factor NF-k B, suggesting cross174 kingdom conservation of central immune responses (Sun et al., 2018). NPR1 is a master 175 regulator of SA perception. Relocation of NPR1 to the nucleus is essential for its function in 176 regulating $P R$ gene expression. NPR1 resides in a large disulfide-bonded oligomeric complex 177 in the cytoplasm in the absence of stress. However, SA accumulation leads to reduction of the 178 intermolecular disulfide bonds by thioredoxin (TRX; (Tada et al., 2008), releasing 179 monomeric NPR1. Reduced NPR1 is then imported into the nucleus (Mou et al., 2003). This 180 process involves phosphorylation at serine 589 (S589) by SnRK2.8, which is important for 181 NPR1 nuclear localization. After entering the nucleus, phosphorylation of NPR1 at serine 55 182 and serine 59 (S55/59) promotes its association with transcription factors such as WRKY and 183 TGA in a redox-dependant manners leading to the expression of pathogenesis-related (PR) 184 genes. Similarly, the glutaredoxin ROXY1 and its homologue ROXY2 are found in the 185 nucleus and cytoplasm (Delorme-Hinoux et al., 2016). In the nucleus, ROXY1 plays a key 186 role in petal development interacting with TOPLESS in a redox-dependent manner, and with 
187 TGA2, TGA3, TGA7 and PERIANTHIA. However, in the case of ROXY1 there is no evidence as yet of redox-regulated movement between the nucleus and cytoplasm.

190 GAPDH is considered to be a quintessential example of a moonlighting protein (Sirover, 191 2012, 2014). It has multiple functions in animals such as DNA stability and control of gene 192 expression, autophagy and apoptosis, in addition to its classic role in glycolysis. The 193 functions of GAPDH in the plant nucleus are not clear, but it may act as a coactivator for 194 gene expression (Hildebrandt et al., 2015). Redox PTMs to the cytosolic GAPDH protein in animals, which block enzyme activity, promote novel cell signalling and transcription functions in the nucleus (Yang and Zhai, 2017) (Zaffagnini et al., 2013). Several GAPDH isoforms exist in different subcellular localizations in plants (Holtgrefe et al., 2008). In particular, the activity and localization of the cytosolic GAPDH isoform (GapC) is controlled by cellular redox state (Bedhomme et al., 2012). Since GapC is also localized in the nucleus, it is suggested that redox modification facilitates transfer to the nucleus in plants as it does in animals (Ortiz-Ortiz et al., 2010). However, the mechanism of nuclear translocation of GapC is unknown although it is thought to involve $S$-sulfhydration, a process that reversibly regulates the function of this protein, in a manner similar to that described in mammalian systems (Aroca et al., 2015) . However, GapC undergoes $S$-nitrosylation, $S$ glutathionylation, $S$-sulfhydration, $S$-sulfenylation as well as other modifications that all occur on the same cysteine residue (Aroca et al., 2017; Bedhomme et al., 2012; Lindermayr et al., 2005; Waszczak et al., 2014). Thus, how each type of PTM modifies GapC to shrift location and/or alternative instigate non-metabolic functions remains to be determined.

209 Catalase (CAT) is a peroxisomal enzyme whose import in mammals is redox-regulated 210 (Walton et al., 2017) and in yeast is dependent on carbon source (Horiguchi et al., 2001). In 211 plants it is classically known as a peroxisomal enzyme but recent evidence suggests that the 212 compartmentation of this central antioxidant enzyme may be more dynamic than the literature 213 acknowledges. The role of CAT as a central 'redox guardian' is well established (Mhamdi et 214 al., 2012). Plant catalases have been shown to interact with a variety of cytosolic proteins 215 including calmodulin (Yang and Poovaiah, 2002), calcium-dependent protein kinase 8 216 (CDPK8) (Zou et al., 2015), salt overly sensitive 2 (SOS2) (Verslues et al., 2007), lesion 217 stimulating disease1 (LSD1) (Li et al., 2013), receptor like cytoplasmic kinase STRK1 (Zhou 218 et al., 2018) and no catalase activity 1 (NCA1) (Hackenberg et al., 2013; Li et al., 2015)

219 (Figure 2). All are integral stress signalling proteins. The ncal mutants, which lack a 
220 functional CAT, are hypersensitive to abiotic stresses. Similarly, the cat2 mutant of

221 Arabidopsis, which lacks the predominant leaf isoform that is essential for the metabolism of

$222 \mathrm{H}_{2} \mathrm{O}_{2}$ produced by photorespiration, activates a wide range of salicylic acid (SA) and 223 jasmonic acid (JA)-dependent responses and displays day-length dependent localised 224 programed cell death (PCD) and resistance to pathogens (Queval et al., 2010). CAT can also 225 be a target for pathogen encoded-effector proteins (Mathioudakis et al., 2013; Murota et al., 226 2017). The fungal effectors PsCRN115 and PsCRN63 both traffic CAT to the nucleus but 227 have opposite biochemical and physiological effects. PsCRN115 stabilises catalase, decreases $228 \mathrm{H}_{2} \mathrm{O}_{2}$ and reduces PCD, whereas PsCRN63 destabilises catalase increases $\mathrm{H}_{2} \mathrm{O}_{2}$ and increases 229 PCD (Zhang et al., 2015). We consider that the CAT interactome with different stress 230 signalling and PCD proteins provides a paradigm for the study for protein relocation. We 231 propose that the location of cytosolically-synthesised CAT is determined by competition 232 among different potential-binding partners as a consequence of reduced import into 233 peroxisomes and/or increased retention of CAT in the cytosol. While sensitivity of 234 peroxisomal protein import to redox status is likely to impact import of all peroxisome 235 proteins, CATALASE which has a non-canonical targeting signal (Mhamdi et al., 2012) 236 (Rymer et al., 2018) may be more sensitive and indeed PEX5, the major peroxisome import 237 receptor, has been proposed to specifically retain mammalian catalase in the cytosol under 238 conditions of oxidative stress (Walton et al., 2017). This property, combined with the 239 potential to interact with an array of cytosolic proteins as shown in Figure 2 could allow 240 swift control of catalase localisation between compartments in such a way as to influence 241 various redox signalling pathways.

242 WHIRLY1 (WHY1) is a member of a small family of ssDNA binding proteins that are 243 specific to the plant kingdom (Desveaux et al., 2005; Desveaux et al., 2004) . The nuclear244 encoded WHY1 protein is targeted to chloroplasts and the nucleus, the nuclear form having 245 the same molecular mass as the processed chloroplast form. In the chloroplasts, WHY1 binds 246 to both DNA and RNA and regulates chloroplast development, plastome copy number and is 247 required for plastome gene expression, intron splicing, ribosome formation and chloroplast to 248 nucleus signaling (Comadira et al., 2015; Prikryl et al., 2008). In the nucleus, WHY1 249 functions in the transcription of senescence and defence genes as well as in the maintenance 250 of telomeres (Yoo et al., 2007). The partitioning of WHY1 between the chloroplasts and 251 nucleus changes during leaf development, WHY1 being predominantly in the chloroplasts of 252 young leaves, while in senescing leaves the protein is localized mainly in the nucleus (Ren $e t$ 
253 al., 2017). This partitioning is regulated at least in part by phosphorylated of WHY1 in the

254 cytosol by a serine/threonine SNF1-related protein kinase called calcineurin B-Like-

255 Interacting Protein Kinase14 (CIPK14). Phosphorylation of WHY1 results in transport to the

256 nucleus (Ren et al., 2017). However, other studies using epitope tagged, transplastomically

257 expressed WHY1 have reported that WHY1 can move from the chloroplasts in the nuclei

258 (Isemer et al., 2012). WHY1 may therefore move from plastids to nucleus upon redox signals

259 (Foyer et al., 2014).

260 Membrane bound transcription factors. As well as soluble proteins, membrane located

261 proteins can be cleaved from their membrane anchor in response to an appropriate signal and

262 relocated (Figure 1). Often these proteins function as transcription factors once liberated

263 from the membrane. ANACO13 and ANAC017 encode Arabidopsis transcription factors

264 belonging to the NON APICAL MERISTEM/ARABIDOPSIS TRANCRIPTION ACTIVATION

265 FACTOR/CUP SHAPED COTYLEDON (NAC) family. These transcription factors mediate

266 ROS-related retrograde signalling originating from mitochondrial complex III. Both proteins

267 contain putative transmembrane domains. They were identified via one hybrid assays as

268 binding to a conserved cis acting regulatory sequence the MDM which mediates

269 mitochondrial retrograde regulation (MRR) during oxidative stress (De Clercq et al., 2013).

270 ANAC013 was shown via chromatin immunoprecipitation to transactivate MDM in planta

271 and upregulate several MITOCHONDRIAL DYSFUNCTION STIMULATION (MDS) genes.

272 GFP-ANAC013 was partially processed and nuclear localised, but while difficult to detect

273 there was a suggestion that the full length protein is ER targeted (De Clercq et al., 2013).

274 ANAC017 was also identified in a screen for loss of response to mitochondrial dysfunction

275 (Ng et al., 2013). It is targeted to the ER and dual tagging experiments showed it is cleaved

276 upon antimycin A treatment, the $\mathrm{N}$ terminal part locates to the nucleus whilst the $\mathrm{C}$ terminal

277 part remained ER associated. ANAC017 function was essential for hydrogen peroxide

278 mediated stress signalling (Ng et al., 2013). Upon perception of redox signals, ANAC013 and

279 ANAC017 are released from the ER and translocated to the nucleus, where they activate MDS

280 genes such as alternative oxidases (AOXS), SOT12, and ANACO13. The latter provides

281 positive feedback regulation of the signalling pathway with enhancement of the signal. The

282 ROS-dependent signalling pathways from chloroplasts and mitochondria merge at

283 RADICAL-INDUCED CELL DEATH1 (RCD1), a nuclear protein that suppresses the

284 activities of the ANAC013 and ANAC017 transcription factors (Shapiguzov et al., 2019). 
286 The chloroplast bound plant homeodomain transcription factor PTM plays a crucial role in

287 chloroplast signalling to the nucleus. Mutants defective in this gene show aberrant responses

288 to treatments such as Norfluazon, high light dibromothymoquonine and Rose Bengal that

289 affect different ROS and the level of reduction of the plastoquinione pool. Full length PTM is

290 located to the chloroplast outer envelope where as a truncated form lacking the TM domain

291 was nuclear. Treatments such as high light and Norfluazon resulted in cleavage of PTM and

292 localisation of the $\mathrm{N}$ terminal domain to the nucleus. Processed PTM was shown to activate

293 ABI4 transcription (Sun et al., 2011).

294 PEX2 is a peroxisome membrane protein with a cytosolically exposed RING domain E3

295 ligase that regulates the recycling and turnover of the PEX5 import receptor through 296 ubiquitination (Burkhart et al., 2014). Interestingly a mutant of Arabidopsis PEX2 (ted3) was

297 recovered as a suppressor of the photomorphogenesis mutant detl (Hu et al., 2002). The

298 mechanism of this remains unknown but an artificially expressed RING domain was found in

299 the nucleus where it interacted with the transcription factor HY5 (Desai et al., 2014). Possible

300 mechanisms could be cleavage of the RING domain and relocation to the nucleus, alternative

301 transcription/translation sites or direct movement between peroxisome and nuclear

302 membrane. Since peroxisomes are important nodes in the cell's antioxidant network and 303 import is under redox control we speculate that PEX2 relocation could represent a potential 304 mechanism for sensing the redox state of peroxisomes and relaying this information to the 305 nucleus.

306 Organelle movement and contact as a mechanism of protein movement

307 Apart from release of proteins from membranes, prevention of import into or promotion of 308 export from organelles, direct transfer of proteins between membrane bound compartments 309 via membrane extensions and contact sites can occur (Pérez-Sancho et al., 2016) (Figure 3).

310 The cytoplasm in plant cells is densely packed and mainly constrained by the vacuole and ER 311 to a narrow cortical zone. Protein transfer between organelles requires regulated release and 312 redirection. Redirection through the cytosol may be slow and prevent bulk delivery. 313 Emerging evidence suggests that the physical interaction between organelles is a requirement

314 for the exchange of small molecules, lipids and proteins in plants as well as in mammals and 315 yeast (Cohen et al., 2018). Coordinated re-arrangement of organelle positioning within the 316 cell could provide a mechanism for shuttling moonlighting proteins between compartments. 317 Targeted 'protected' delivery from degradation, or potential reversal of the PTM, could be 
318 provided through the formation of a micro-environment between organelles that allows for

319 exchanging proteins through a narrow 10-40nm cytoplasmic zone at the membrane contact

320 site interface. Repositioning of organelles could also allow neighbouring organelles to signal

321 to one another to regulate protein exchange. Organelle movement and positioning, which play

322 essential roles in plant responses to light and other metabolic and environmental stimuli, are

323 linked to the cellular redox status.

\section{Redox-dependent formation of of stromules, matrixules and peroxules}

325 Chloroplasts, mitochondria and peroxisomes are pleomorphic, dynamic organelles that 326 produce tubules upon stress. Like membrane contact sites (MCS) these tubules allow 327 positioning of the organelles in relation to each other within the cell and might be involved in 328 the exchange of metabolites or macromolecues. For example, stroma-filled tubules called 329 stromules (Figure 4) extend from the envelope of all plastid types. ROS increase peroxisome 330 speed, resulting in membrane extensions (peroxules), which could facilitate contact with 331 other organelles including chloroplasts (Gao et al., 2016; Rodriguez-Serrano et al., 2016;

332 Rodriguez-Serrano et al., 2009). However, the cargo of the tubular structures and the nature 333 of the potential signals (metabolic or proteinaceous) that are released is largely unknown.

334 Stromules allow actin-mediated anchoring of chloroplasts at different locations within the 335 cell to facilitate specific functions. For example, they can extend along microtubules to guide 336 chloroplast movement to the nucleus during innate immunity responses. The application of 337 hydrogen peroxide $\left(\mathrm{H}_{2} \mathrm{O}_{2}\right)$ resulted in rapid stromule formation in Arabidopsis leaves (Caplan 338 et al., 2015). The accumulation of ROS, like other pro-defense molecules, is sufficient to 339 induce stromule formation leading to the development of direct contact points between the 340 chloroplasts and nuclei (Caplan et al., 2015). In addition, other direct contact sites between 341 chloroplasts and nuclei that are induced by high light have been suggested to allow 342 movement of $\mathrm{H}_{2} \mathrm{O}_{2}$ to the nucleus from attached chloroplasts (Exposito-Rodriguez et al., 343 2017). Arogenate dehydratase (ADT) 2 which catalyzes the final step in phenylalanine 344 biosynthesis localizes to stromules and also helps in dividing chloroplasts, whilst ADT5 is 345 proposed to traffic to nuclei via stromules, (Bross et al., 2017). Another interesting example 346 of possible organelle to organelle transport of proteins via membrane extensions is the triacyl 347 glycerol lipase SDP1 which is proposed to move from peroxisomes to oil bodies in a tubule348 and retromer- dependent process (Thazar-Poulot et al., 2015). 
349 Mitochondria produce structures that are partly homologous to the chloroplast stromules, in 350 (Schmidt et al., 2016) response to light and other stimuli in an endoplasmic reticulum (ER)351 mediated manner. The protrusion-driven movement and positioning is considered to promote 352 the inter-compartmental trafficking of metabolites and proteins but there remains a paucity of 353 data on which proteins are trafficked and the mechanisms involved. ROS and redox cues 354 modify microtubule orientation and behaviour within cells, as well as the operation of protein

355 import and export machineries (Schmidt et al., 2016). So far, it remains to be determined if 356 these organelle-derived tubular structures are involved in direct exchange of metabolites or 357 macromolecules between compartments, or might rather have a supportive function in the 358 communication between organelles by acting as an cellular anchor to temporary fix their relative position to each other.

\section{Conclusions and Perspectives}

362 The regulation of metabolism is shaped by compartmentalization in all cell types. Indeed, the 363 compartmentalization of cell structure is a prerequisite for establishing stable metabolic states 364 of different cell fates (Harrington et al., 2013). Higher plants show a particularly high degree 365 of cellular compartmentalization because of the presence of compartments such as 366 chloroplasts, other plastids and vacuoles. Until recently the paucity of experimental data on 367 subcellular protein distribution has limited our understanding of the capacity and ability of 368 proteins to move between different intracellular compartments. Recent years have seen a step 369 change in our knowledge of proteins that perform more than one cellular function. The term 370 given to such proteins is 'moonlighting', but this description is limited because it does not apply to all proteins that move between different cellular compartments. Moreover, it has become increasingly apparent that protein localisation is not fixed and a high proportion of cellular proteins have the potential to move between compartments in response to specific triggers. In some cases this movement is the basis for an alternative cellular function. We have provided a list of examples of proteins that are considered to undergo redox-regulated movements between compartments. This may be the tip of iceberg because there are many proteins in the literature that are suggested to undergo inter-compartmental switching in response to appropriate triggers. Arabidopsis hexokinase 1, for example, which is located at the outer mitochondrial membrane, was suggested to be translocated between mitochondrion and nucleus, upon perception of sugar signals or methyl-jasmonate, in a manner that is linked 
381 to mitochondrial ROS production (Claeyssen and Rivoal, 2007; Xiang et al., 2011). At

382 present however we have only a fragmented picture with relatively few well characterised

383 examples of proteins in plants that change compartment in order to moonlight, and the

384 mechanisms by which they do so are largely unexplored. Redox PTMs are likely to be a key

385 driver for inter-compartmental shifts of antioxidant and redox-regulated proteins that can

386 integrate metabolic processes and influence genetic and epigenetic controls of plant growth

387 and stress tolerance.

388

389 Author contributions: $\mathrm{CH}$. Foyer and A Baker proposed the original idea and wrote the first

390 draft of the manuscript text. All authors polished and contributed to the final manuscript text.

391 A Baker produced figures 1 and 2, and table 1.J. Schippers produced Figure 3 and

392 harmonised the style of all the figures. M Wright produced Box I.

394 Acknowledgements

395 The authors gratefully acknowledge Prof Patricia Conklin State University of New York

396 College at Cortland for the image in Figure 4. CHF thanks BBSRC (UK) for financial

397 support (BB/N004914/1). 


\section{FIGURE LEGENDS}

\section{Figure 1 Potential mechanisms of protein relocation}

Proteins can potentially change their cellular localisation by a number of mechanisms. Proteins which have been inserted into an organelle membrane can be released by regulated proteolysis as described for the chloroplast envelope localised PTM1 and ER membrane localised ANAC013 and ANAC017. All organelles appear to have an ER associated degradation (ERAD)-like pathway which exports proteins in an ubiquitin dependent manner for degradation by the proteasome. Whether proteins can be exported and escape degradation to be retargeted elsewhere in the cell is currently unknown. Ubquitination on membrane components can also lead to organelle turnover. Transport by direct organelle contacts is also a possible mechanism. Proteins normally targeted to an organelle can be prevented from import through either modification of the import machinery or modification of the cyctosolic precursor form of the protein. This can include post translational modifications (PTMs) which can modify the targeting signal or affect interactions with other binding partners. See text for further details.

Figure 2 Switching partners: model for regulation of catalase localisation through interaction with different binding proteins.

Several cytosolic proteins have been reported to interact with plant catalases. Redox mediated PTMs could alter the affinity of catalase for different binding partners leading to a change in distribution between peroxisomes, cytosol and nucleus. See text for further details.

Figure 3 Organelle interactions through protrusions and membrane contact sites

Organelle-organelle interactions in cells occurs by either the formation of membrane contact sites (MCS) between organelles or by the formation of tubular structures by one organelle. MCSs are known to occur between mitochondria and plastids, mitochondria and the ER, and plastids and the ER. In addition, mitochondria, plastids and peroxisomes form tubular structures. In the case of plastids stromules are formed especially in the direction of the nucleus. Mitochondria form matrixules within ER structures and peroxisomes form peroxules in the vicinity of plastids, mitochondria and the nucleus. Both MCS and the tubular structures will mediate communications between organelles by exchanging signaling molecules, metabolites or potentially even proteins. 
Figure 4. Stromule formation in $N$. benthamiana leaves upon transient over-expression of GFP-tagged plastid outer membrane protein AtLACS9 (At1g77560).

A. tumefaciens carrying AtLACS9-GFP (Breuers et al., 2012) and a second strain carrying the P19 silencing suppressor construct (Takeda et al., 2002) were co-infiltrated at 0.4 OD each into 7-week-old N. benthamiana leaves. Fluorescence imaging was done at $72 \mathrm{hrs.} \mathrm{post}$ infiltration with a Zeiss LSM710 confocal microscope. Image is a maximum projection of 10 optical sections. GFP (green); chlorophyll autofluorescence (red).

Figure 5. . Methods to identify the sulfenome. A. Protein-based probe YAP1C. B. Small molecule-based probe DYn-2. See Box I text for detail. 


\section{Box I - key developments to help understand reversible oxidative modifications in plants.}

\section{Genetically-encoded protein-based tools to trap sulfenylated proteins in situ.}

$S$-Sulfenylation (protein-SOH) is a reversible oxidative PTM that acts as regulatory switch in signal transduction pathways. However the global "sulfenome" is particularly challenging to detect as this PTM is transient, unstable, and prone to over-oxidation even during cell lysis. Recently a genetically-encoded tool to capture $S$-sulfenylated proteins was developed (Waszczak et al., 2014). The cysteine-rich domain of the yeast transcription factor YAP1 forms disulfides with $S$-sulfenic acid modifications on its cognate signalling protein; fusion of this domain with an affinity tag creates a tool to capture and enrich $S$-sulfenylated proteins in vivo (Figure 5, A). YAP1 can be expressed in cells, with control cells expressing a catalytically inactive version (YAP1A), and, following cell lysis, downstream affinity purification used to identify disulfide linked proteins. The authors detected $\sim 100$ sulfenylated proteins in Arabidopsis cell suspensions exposed to $\mathrm{H}_{2} \mathrm{O}_{2}$ oxidative stress (Waszczak et al., 2014).

\section{Small molecule-based probes to detect the sulfenome.}

A complementary approach exploits the chemoselective reaction of small molecules based on dimedone with sulfenic acid. Whilst YAP1C recognition of sulfenic acids is dependent on protein-protein interactions, a small molecule is in principle more general and able to access more sulfenylation sites. The Carroll group have pioneered the use of DYn-2, a dimedone probe that is small yet ready appended to affinity tags such as biotin by click chemistry for enrichment of sulfenylated proteins (Figure 5, B) (Paulsen et al., 2011). Akter et al. applied DYn-2 is Arabidopsis cultures (Akter et al., 2015), identifying 226 sulfenylation events in response to oxidative stress, and, more recently, in plants (Akter et al., 2017). 


\section{References}

Akter S, Carpentier S, Van Breusegem F, Messens J. 2017. Identification of dimedonetrapped sulfenylated proteins in plants under stress. Biochem Biophys Rep 9, 106-113.

Akter S, Huang J, Bodra N, De Smet B, Wahni K, Rombaut D, Pauwels J, Gevaert K, Carroll K, Van Breusegem F, Messens J. 2015. DYn-2 Based Identification of Arabidopsis Sulfenomes. Mol Cell Proteomics 14, 1183-1200.

Aroca A, Gotor C, Romero LC, Schneider M, Scheibe R. 2017. Hydrogen Sulfide Regulates the Cytosolic/Nuclear Partitioning of Glyceraldehyde-3-Phosphate Dehydrogenase by Enhancing its Nuclear Localization. Plant and Cell Physiology 58, 983-992.

Aroca Á, Serna A, Gotor C, Romero LC. 2015. S-Sulfhydration: A Cysteine Posttranslational Modification in Plant Systems. Plant Physiology 168, 334-342.

Bedhomme M, Adamo M, Marchand Christophe H, Couturier J, Rouhier N, Lemaire Stéphane D, Zaffagnini M, Trost P. 2012. Glutathionylation of cytosolic glyceraldehyde-3phosphate dehydrogenase from the model plant Arabidopsis thaliana is reversed by both glutaredoxins and thioredoxins in vitro. Biochemical Journal 445, 337-347.

Bolter B, Soll J, Schwenkert S. 2015. Redox meets protein trafficking. Biochim Biophys Acta 1847, 949-956.

Boukouris AE, Zervopoulos SD, Michelakis ED. 2016. Metabolic Enzymes Moonlighting in the Nucleus: Metabolic Regulation of Gene Transcription. Trends in Biochemical Sciences 41, 712-730.

Bragoszewski P, Turek M, Chacinska A. 2017. Control of mitochondrial biogenesis and function by the ubiquitin-proteasome system. Open Biol 7, 10.1098/rsob.170007.

Breuers FK, Brautigam A, Geimer S, Welzel UY, Stefano G, Renna L, Brandizzi F, Weber AP. 2012. Dynamic Remodeling of the Plastid Envelope Membranes - A Tool for Chloroplast Envelope in vivo Localizations. Front Plant Sci 3, 7.

Bross CD, Howes TR, Abolhassani Rad S, Kljakic O, Kohalmi SE. 2017. Subcellular localization of Arabidopsis arogenate dehydratases suggests novel and non-enzymatic roles. Journal of experimental botany 68, 1425-1440.

Burkhart SE, Kao Y-T, Bartel B. 2014. Peroxisomal Ubiquitin-Protein Ligases Peroxin2 and Peroxin10 Have Distinct But Synergistic Roles in Matrix Protein Import and Peroxin5 Retrotranslocation in Arabidopsis. Plant Physiology 166, 1329-1344.

Caplan JL, Kumar AS, Park E, Padmanabhan MS, Hoban K, Modla S, Czymmek K, Dinesh-Kumar SP. 2015. Chloroplast Stromules Function during Innate Immunity. Developmental cell 34, 45-57.

Chapple CE, Robisson B, Spinelli L, Guien C, Becker E, Brun C. 2015. Extreme multifunctional proteins identified from a human protein interaction network. Nat Commun 6, 7412 .

Chong Yolanda T, Koh Judice LY, Friesen H, Kaluarachchi Duffy S, Cox Michael J, Moses A, Moffat J, Boone C, Andrews Brenda J. 2015. Yeast Proteome Dynamics from Single Cell Imaging and Automated Analysis. Cell 161, 1413-1424.

Claeyssen É, Rivoal J. 2007. Isozymes of plant hexokinase: Occurrence, properties and functions. Phytochemistry 68, 709-731.

Cohen S, Valm AM, Lippincott-Schwartz J. 2018. Interacting organelles. Curr Opin Cell Biol 53, 84-91.

Comadira G, Rasool B, Kaprinska B, García BM, Morris J, Verrall SR, Bayer M, Hedley PE, Hancock RD, Foyer CH. 2015. WHIRLY1 Functions in the Control of Responses to Nitrogen Deficiency But Not Aphid Infestation in Barley. Plant Physiology 168, 1140-1151. 
Czarnocka W, Van Der Kelen K, Willems P, Szechyńska-Hebda M, Shahnejat-Bushehri S, Balazadeh S, Rusaczonek A, Mueller-Roeber B, Van Breusegem F, Karpiński S. 2017. The dual role of LESION SIMULATING DISEASE 1 as a condition-dependent scaffold protein and transcription regulator. Plant, Cell \& Environment 40, 2644-2662.

Dang X, Yu P, Li Y, Yang Y, Zhang Y, Ren H, Chen B, Lin D. 2018. Reactive oxygen species mediate conical cell shaping in Arabidopsis thaliana petals. PLoS Genet 14, e1007705.

De Clercq I, Vermeirssen V, Van Aken O, Vandepoele K, Murcha MW, Law SR, Inzé A, Ng S, Ivanova A, Rombaut D, van de Cotte B, Jaspers P, Van de Peer Y, Kangasjärvi J, Whelan J, Van Breusegem F. 2013. The Membrane-Bound NAC Transcription Factor ANAC013 Functions in Mitochondrial Retrograde Regulation of the Oxidative Stress Response in Arabidopsis. The Plant Cell 25, 3472-3490.

de Torres Zabala M, Littlejohn G, Jayaraman S, Studholme D, Bailey T, Lawson T, Tillich M, Licht D, Bolter B, Delfino L, Truman W, Mansfield J, Smirnoff N, Grant M. 2015. Chloroplasts play a central role in plant defence and are targeted by pathogen effectors. Nat Plants 1, 15074.

Delorme-Hinoux V, Bangash SAK, Meyer AJ, Reichheld J-P. 2016. Nuclear thiol redox systems in plants. Plant Science 243, 84-95.

Desai M, Kaur N, Hu J. 2014. Ectopic expression of the RING domain of the Arabidopsis peroxin2 protein partially suppresses the phenotype of the photomorphogenic mutant deetiolated1. PLoS One 9, e108473.

Desveaux D, Maréchal A, Brisson N. 2005. Whirly transcription factors: defense gene regulation and beyond. Trends in Plant Science 10, 95-102.

Desveaux D, Subramaniam R, Després C, Mess J-N, Lévesque C, Fobert PR, Dangl JL, Brisson N. 2004. A 'Whirly' Transcription Factor Is Required for Salicylic Acid-Dependent Disease Resistance in Arabidopsis. Developmental cell 6, 229-240.

Exposito-Rodriguez M, Laissue PP, Yvon-Durocher G, Smirnoff N, Mullineaux PM. 2017. Photosynthesis-dependent $\mathrm{H}_{2} \mathrm{O}_{2}$ transfer from chloroplasts to nuclei provides a highlight signalling mechanism. Nat Commun 8, 49.

Foyer CH, Allen JF. 2003. Lessons from Redox Signaling in Plants. Antioxidants \& Redox Signaling 5, 3-5.

Foyer CH, Karpinska B, Krupinska K. 2014. The functions of WHIRLY1 and REDOXRESPONSIVE TRANSCRIPTION FACTOR 1 in cross tolerance responses in plants: a hypothesis. Philos Trans R Soc Lond B Biol Sci 369, 20130226.

Gao H, Metz J, Teanby NA, Ward AD, Botchway SW, Coles B, Pollard MR, Sparkes I. 2016. In Vivo Quantification of Peroxisome Tethering to Chloroplasts in Tobacco Epidermal Cells Using Optical Tweezers. Plant Physiol 170, 263-272.

Grou CP, Carvalho AF, Pinto MP, Huybrechts SJ, Sá-Miranda C, Fransen M, Azevedo JE. 2009. Properties of the ubiquitin-pex $5 p$ thiol ester conjugate. The Journal of biological chemistry 284, 10504-10513.

Hackenberg T, Juul T, Auzina A, Gwiżdż S, Małolepszy A, Van Der Kelen K, Dam S, Bressendorff S, Lorentzen A, Roepstorff P, Lehmann Nielsen K, Jørgensen J-E, Hofius D, Breusegem FV, Petersen M, Andersen SU. 2013. Catalase and NO CATALASE ACTIVITY1 Promote Autophagy-Dependent Cell Death in Arabidopsis. The Plant Cell 25, 4616-4626.

Harbauer AB, Zahedi RP, Sickmann A, Pfanner N, Meisinger C. 2014. The protein import machinery of mitochondria-a regulatory hub in metabolism, stress, and disease. Cell Metab 19, 357-372. 
Harrington HA, Feliu E, Wiuf C, Stumpf MPH. 2013. Cellular compartments cause multistability and allow cells to process more information. Biophysical journal 104, 18241831.

He H, Lee M-C, Zheng L-L, Zheng L, Luo Y. 2013. Integration of the metabolic/redox state, histone gene switching, DNA replication and S-phase progression by moonlighting metabolic enzymes. Bioscience reports 33, e00018-e00018.

Hildebrandt T, Knuesting J, Berndt C, Morgan B, Scheibe R. 2015. Cytosolic thiol switches regulating basic cellular functions: GAPDH as an information hub? Biological Chemistry, Vol. 396, 523.

Holtgrefe S, Gohlke J, Starmann J, Druce S, Klocke S, Altmann B, Wojtera J, Lindermayr C, Scheibe R. 2008. Regulation of plant cytosolic glyceraldehyde 3-phosphate dehydrogenase isoforms by thiol modifications. Physiologia plantarum 133, 211-228.

Horiguchi H, Yurimoto H, Goh T-K, Nakagawa T, Kato N, Sakai Y. 2001. Peroxisomal Catalase in the Methylotrophic Yeast Candida boidinii: Transport Efficiency and Metabolic Significance. Journal of Bacteriology 183, 6372-6383.

Hu J, Aguirre M, Peto C, Alonso J, Ecker J, Chory J. 2002. A role for peroxisomes in photomorphogenesis and development of Arabidopsis. Science 297, 405-409.

Isemer R, Mulisch M, Schafer A, Kirchner S, Koop HU, Krupinska K. 2012. Recombinant Whirly1 translocates from transplastomic chloroplasts to the nucleus. FEBS Lett 586, 85-88.

Kaludercic N, Deshwal S, Di Lisa F. 2014. Reactive oxygen species and redox compartmentalization. Front Physiol 5, 285.

Kao YT, Gonzalez KL, Bartel B. 2018. Peroxisome Function, Biogenesis, and Dynamics in Plants. Plant Physiol 176, 162-177.

Kirstein J, Morito D, Kakihana T, Sugihara M, Minnen A, Hipp MS, NussbaumKrammer C, Kasturi P, Hartl FU, Nagata K, Morimoto RI. 2015. Proteotoxic stress and ageing triggers the loss of redox homeostasis across cellular compartments. EMBO J 34, 2334-2349.

Li J, Liu J, Wang G, Cha J-Y, Li G, Chen S, Li Z, Guo J, Zhang C, Yang Y, Kim W-Y, Yun D-J, Schumaker KS, Chen Z, Guo Y. 2015. A Chaperone Function of NO CATALASE ACTIVITY1 Is Required to Maintain Catalase Activity and for Multiple Stress Responses in Arabidopsis. The Plant Cell 27, 908-925.

Li Y, Chen L, Mu J, Zuo J. 2013. LESION SIMULATING DISEASE1 Interacts with Catalases to Regulate Hypersensitive Cell Death in Arabidopsis. Plant Physiology 163, 10591070.

Liebthal M, Maynard D, Dietz K-J. 2018. Peroxiredoxins and Redox Signaling in Plants. Antioxidants \& Redox Signaling 28, 609-624.

Lindermayr C, Saalbach G, Durner J. 2005. Proteomic Identification of S-Nitrosylated Proteins in Arabidopsis. Plant Physiology 137, 921-930.

Ling Q, Huang W, Baldwin A, Jarvis P. 2012. Chloroplast biogenesis is regulated by direct action of the ubiquitin-proteasome system. Science 338, 655-659.

Ling Q, Jarvis P. 2015. Regulation of Chloroplast Protein Import by the Ubiquitin E3 Ligase SP1 Is Important for Stress Tolerance in Plants. Curr Biol 25, 2527-2534.

Ling Q, Jarvis P. 2016. Plant Signaling: Ubiquitin Pulls the Trigger on Chloroplast Degradation. Curr Biol 26, R38-40.

Marondedze C, Thomas L, Serrano NL, Lilley KS, Gehring C. 2016. The RNA-binding protein repertoire of Arabidopsis thaliana. Sci Rep 6, 29766.

Mathioudakis MM, Veiga RSL, Canto T, Medina V, Mossialos D, Makris AM, Livieratos I. 2013. Pepino mosaic virus triple gene block protein 1 (TGBp1) interacts with 
and increases tomato catalase 1 activity to enhance virus accumulation. Molecular Plant Pathology 14, 589-601.

Mhamdi A, Noctor G, Baker A. 2012. Plant catalases: Peroxisomal redox guardians. Archives of Biochemistry and Biophysics 525, 181-194.

Mhamdi A, Van Breusegem F. 2018. Reactive oxygen species in plant development. Development 145.

Min K-W, Lee S-H, Baek SJ. 2016. Moonlighting proteins in cancer. Cancer Letters 370, 108-116.

Moeder W, del Pozo O, Navarre DA, Martin GB, Klessig DF. 2007. Aconitase plays a role in regulating resistance to oxidative stress and cell death in Arabidopsis and Nicotiana benthamiana. Plant Molecular Biology 63, 273-287.

Monaghan RM, Whitmarsh AJ. 2015. Mitochondrial Proteins Moonlighting in the Nucleus. Trends Biochem Sci 40, 728-735.

Mou Z, Fan W, Dong X. 2003. Inducers of Plant Systemic Acquired Resistance Regulate NPR1 Function through Redox Changes. Cell 113, 935-944.

Murota K, Shimura H, Takeshita M, Masuta C. 2017. Interaction between Cucumber mosaic virus $2 \mathrm{~b}$ protein and plant catalase induces a specific necrosis in association with proteasome activity. Plant Cell Reports 36, 37-47.

Nargund AM, Pellegrino MW, Fiorese CJ, Baker BM, Haynes CM. 2012. Mitochondrial import efficiency of ATFS-1 regulates mitochondrial UPR activation. Science 337, 587-590.

Ng S, Ivanova A, Duncan O, Law SR, Van Aken O, De Clercq I, Wang Y, Carrie C, Xu L, Kmiec B, Walker H, Van Breusegem F, Whelan J, Giraud E. 2013. A MembraneBound NAC Transcription Factor, ANAC017, Mediates Mitochondrial Retrograde Signaling in Arabidopsis. The Plant Cell 25, 3450-3471.

Noctor G, Foyer CH. 2016. Intracellular Redox Compartmentation and ROS-Related Communication in Regulation and Signaling. Plant Physiology 171, 1581-1592.

Ortiz-Ortiz MA, Morán JM, Ruiz-Mesa LM, Bravo-San Pedro JM, Fuentes JM. 2010. Paraquat Exposure Induces Nuclear Translocation of Glyceraldehyde-3-Phosphate Dehydrogenase (GAPDH) and the Activation of the Nitric Oxide-GAPDH-Siah Cell Death Cascade. Toxicological Sciences 116, 614-622.

Paulsen CE, Truong TH, Garcia FJ, Homann A, Gupta V, Leonard SE, Carroll KS. 2011. Peroxide-dependent sulfenylation of the EGFR catalytic site enhances kinase activity. Nat Chem Biol 8, 57-64.

Pérez-Sancho J, Tilsner J, Samuels AL, Botella MA, Bayer EM, Rosado A. 2016. Stitching Organelles: Organization and Function of Specialized Membrane Contact Sites in Plants. Trends in Cell Biology 26, 705-717.

Pool MR, López-Huertas E, Horng J-T, Baker A. 1998. NADPH is a specific inhibitor of protein import into glyoxysomes. The Plant Journal 15, 1-14.

Prikryl J, Watkins KP, Friso G, van Wijk KJ, Barkan A. 2008. A member of the Whirly family is a multifunctional RNA- and DNA-binding protein that is essential for chloroplast biogenesis. Nucleic acids research 36, 5152-5165.

Queval G, Chaouch S, Noctor G, Mhamdi A, Van Breusegem F, Vanderauwera S. 2010. Catalase function in plants: a focus on Arabidopsis mutants as stress-mimic models. Journal of experimental botany 61, 4197-4220.

Ren Y, Li Y, Jiang Y, Wu B, Miao Y. 2017. Phosphorylation of WHIRLY1 by CIPK14 Shifts Its Localization and Dual Functions in Arabidopsis. Molecular Plant 10, 749-763.

Rodriguez-Serrano M, Romero-Puertas MC, Sanz-Fernandez M, Hu J, Sandalio LM. 2016. Peroxisomes Extend Peroxules in a Fast Response to Stress via a Reactive Oxygen Species-Mediated Induction of the Peroxin PEX11a. Plant Physiol 171, 1665-1674. 
Rodriguez-Serrano M, Romero-Puertas MC, Sparkes I, Hawes C, del Rio LA, Sandalio LM. 2009. Peroxisome dynamics in Arabidopsis plants under oxidative stress induced by cadmium. Free Radic Biol Med 47, 1632-1639.

Rymer Ł, Kempiński B, Chełstowska A, Skoneczny M. 2018. The budding yeast Pex5p receptor directs Fox $2 p$ and Cta1p into peroxisomes via its N-terminal region near the FxxxW domain. Journal of Cell Science 131, jcs216986.

Schimmeyer J, Bock R, Meyer EH. 2016. L-Galactono-1,4-lactone dehydrogenase is an assembly factor of the membrane arm of mitochondrial complex I in Arabidopsis. Plant Molecular Biology 90, 117-126.

Schmid L-M, Ohler L, Möhlmann T, Brachmann A, Muiño JM, Leister D, Meurer J, Manavski N. 2019. PUMPKIN, the Sole Plastid UMP Kinase, Associates with Group II Introns and Alters Their Metabolism. Plant Physiology 179, 248-264.

Schmidt R, Kunkowska AB, Schippers JHM. 2016. Role of Reactive Oxygen Species during Cell Expansion in Leaves. Plant Physiology 172, 2098-2106.

Schmidt R, Schippers JHM. 2015. ROS-mediated redox signaling during cell differentiation in plants. Biochimica et Biophysica Acta (BBA) - General Subjects 1850, 1497-1508.

Schreier TB, Cléry A, Schläfli M, Galbier F, Stadler M, Demarsy E, Albertini D, Maier BA, Kessler F, Hörtensteiner S, Zeeman SC, Kötting O. 2018. Plastidial NAD-Dependent Malate Dehydrogenase: A Moonlighting Protein Involved in Early Chloroplast Development through Its Interaction with an FtsH12-FtsHi Protease Complex. The Plant Cell 30, 17451769.

Seo PJ, Kim SG, Park CM. 2008. Membrane-bound transcription factors in plants. Trends Plant Sci 13, 550-556.

Shapiguzov A, Vainonen JP, Hunter K, Tossavainen H, Tiwari A, Järvi S, Hellman M, Aarabi F, Alseekh S, Wybouw B, Van Der Kelen K, Nikkanen L, Krasensky-Wrzaczek J, Sipari N, Keinänen M, Tyystjärvi E, Rintamäki E, De Rybel B, Salojärvi J, Van Breusegem F, Fernie AR, Brosché M, Permi P, Aro E-M, Wrzaczek M, Kangasjärvi J. 2019. Arabidopsis RCD1 coordinates chloroplast and mitochondrial functions through interaction with ANAC transcription factors. eLife 8, e43284.

Sirover MA. 2012. Subcellular dynamics of multifunctional protein regulation: Mechanisms of GAPDH intracellular translocation. Journal of Cellular Biochemistry 113, 2193-2200.

Sirover MA. 2014. Structural analysis of glyceraldehyde-3-phosphate dehydrogenase functional diversity. The International Journal of Biochemistry \& Cell Biology 57, 20-26.

Sun X, Feng P, Xu X, Guo H, Ma J, Chi W, Lin R, Lu C, Zhang L. 2011. A chloroplast envelope-bound PHD transcription factor mediates chloroplast signals to the nucleus. Nat Commun 2, 477.

Sun Y, Detchemendy TW, Pajerowska-Mukhtar KM, Mukhtar MS. 2018. NPR1 in JazzSet with Pathogen Effectors. Trends in Plant Science 23, 469-472.

Tada Y, Spoel SH, Pajerowska-Mukhtar K, Mou Z, Song J, Wang C, Zuo J, Dong X. 2008. Plant Immunity Requires Conformational Charges of NPR1 via S-Nitrosylation and Thioredoxins. Science 321, 952-956.

Takeda A, Sugiyama K, Nagano H, Mori M, Kaido M, Mise K, Tsuda S, Okuno T. 2002. Identification of a novel RNA silencing suppressor, NSs protein of Tomato spotted wilt virus. FEBS Lett 532, 75-79.

Thazar-Poulot N, Miquel M, Fobis-Loisy I, Gaude T. 2015. Peroxisome extensions deliver the Arabidopsis SDP1 lipase to oil bodies. Proceedings of the National Academy of Sciences 112, 4158-4163.

Thul PJ, Akesson L, Wiking M, Mahdessian D, Geladaki A, Ait Blal H, Alm T, Asplund A, Bjork L, Breckels LM, Backstrom A, Danielsson F, Fagerberg L, Fall J, Gatto L, 22 
Gnann C, Hober S, Hjelmare M, Johansson F, Lee S, Lindskog C, Mulder J, Mulvey CM, Nilsson P, Oksvold P, Rockberg J, Schutten R, Schwenk JM, Sivertsson A, Sjostedt E, Skogs M, Stadler C, Sullivan DP, Tegel H, Winsnes C, Zhang C, Zwahlen M, Mardinoglu A, Ponten F, von Feilitzen K, Lilley KS, Uhlen M, Lundberg E. 2017. A subcellular map of the human proteome. Science $\mathbf{3 5 6}$.

Tsang CK, Liu Y, Thomas J, Zhang Y, Zheng XF. 2014. Superoxide dismutase 1 acts as a nuclear transcription factor to regulate oxidative stress resistance. Nat Commun 5, 3446.

Verslues PE, Batelli G, Grillo S, Agius F, Kim YS, Zhu J, Agarwal M, Katiyar-Agarwal S, Zhu JK. 2007. Interaction of SOS2 with nucleoside diphosphate kinase 2 and catalases reveals a point of connection between salt stress and $\mathrm{H} 2 \mathrm{O} 2$ signaling in Arabidopsis thaliana. Mol Cell Biol 27, 7771-7780.

Virdi KS, Laurie JD, Xu Y-Z, Yu J, Shao M-R, Sanchez R, Kundariya H, Wang D, Riethoven J-JM, Wamboldt Y, Arrieta-Montiel MP, Shedge V, Mackenzie SA. 2015. Arabidopsis MSH1 mutation alters the epigenome and produces heritable changes in plant growth. Nature communications 6, 6386-6386.

Walton PA, Brees C, Lismont C, Apanasets O, Fransen M. 2017. The peroxisomal import receptor PEX5 functions as a stress sensor, retaining catalase in the cytosol in times of oxidative stress. Biochim Biophys Acta Mol Cell Res 1864, 1833-1843.

Waszczak C, Akter S, Eeckhout D, Persiau G, Wahni K, Bodra N, Van Molle I, De Smet B, Vertommen D, Gevaert $K$, De Jaeger G, Van Montagu M, Messens J, Van Breusegem F. 2014. Sulfenome mining in Arabidopsis thaliana. Proc Natl Acad Sci U S A 111, 11545-11550.

Xiang L, Li Y, Rolland F, Van den Ende W. 2011. Neutral invertase, hexokinase and mitochondrial ROS homeostasis: emerging links between sugar metabolism, sugar signaling and ascorbate synthesis. Plant signaling \& behavior 6, 1567-1573.

Yang SS, Zhai QH. 2017. Cytosolic GAPDH: a key mediator in redox signal transduction in plants.

Yang T, Poovaiah BW. 2002. Hydrogen peroxide homeostasis: Activation of plant catalase by calcium/calmodulin. Proceedings of the National Academy of Sciences 99, 4097-4102.

Yoo HH, Kwon C, Lee MM, Chung IK. 2007. Single-stranded DNA binding factor AtWHY1 modulates telomere length homeostasis in Arabidopsis. The Plant Journal 49, 442451.

Zaffagnini M, Fermani S, Costa A, Lemaire S, Trost P. 2013. Plant cytoplasmic GAPDH: redox post-translational modifications and moonlighting properties. Frontiers in Plant Science 4, 10.3389/fpls.2013.00450.

Zhang M, Li Q, Liu T, Liu L, Shen D, Zhu Y, Liu P, Zhou JM, Dou D. 2015. Two cytoplasmic effectors of Phytophthora sojae regulate plant cell death via interactions with plant catalases. Plant Physiol 167, 164-175.

Zhou YB, Liu C, Tang DY, Yan L, Wang D, Yang YZ, Gui JS, Zhao XY, Li LG, Tang XD, Yu F, Li JL, Liu LL, Zhu YH, Lin JZ, Liu XM. 2018. The Receptor-Like Cytoplasmic Kinase STRK1 Phosphorylates and Activates CatC, Thereby Regulating $\mathrm{H}_{2} \mathrm{O}_{2}$ Homeostasis and Improving Salt Tolerance in Rice. Plant Cell 30, 1100-1118.

Zou J-J, Li X-D, Ratnasekera D, Wang C, Liu W-X, Song L-F, Zhang W-Z, Wu W-H. 2015. Arabidopsis CALCIUM-DEPENDENT PROTEIN KINASE8 and CATALASE3 Function in Abscisic Acid-Mediated Signaling and $\mathrm{H}_{2} \mathrm{O}_{2}$ Homeostasis in Stomatal Guard Cells under Drought Stress. The Plant Cell 27, 1445-1460. 
bioRxiv preprint doi: https://doi.org/10.1101/588269; this version posted March 25, 2019. The copyright holder for this preprint (which was not certified by peer review) is the author/funder, who has granted bioRxiv a license to display the preprint in perpetuity. It is made available under aCC-BY-ND 4.0 International license. 
Table 1 Moonlighting proteins in plants

\begin{tabular}{|c|c|c|c|c|}
\hline Protein & Function & Location & Moonlighting function & Reference \\
\hline PUMPKIN & Plastid UMP kinase & plastid & RNA binding Plastid transcript introns & (Schmid et al., 2019) \\
\hline WHIRLY1 & $\begin{array}{l}\text { Nuclear encoded } \\
\text { transcription factor } \\
\text { involved in pathogen } \\
\text { response }\end{array}$ & $\begin{array}{l}\text { Nucleus/ } \\
\text { plastid }\end{array}$ & RNA processing in the plastid & $\begin{array}{l}\text { (Foyer et al., 2014; } \\
\text { Isemer et al., 2012) }\end{array}$ \\
\hline PEX2 & Ubiquitin E3 ligase & $\begin{array}{l}\text { Peroxisome } \\
\text { membrane/ } \\
\text { nucleus? }\end{array}$ & $\begin{array}{l}\text { ted3 gain of function mutant suppresses } \\
\text { photomorphogenesis mutant det1 and evidence for } \\
\text { interaction with Hy5 TF in nucleus but } \\
\text { mechanism/function unknown }\end{array}$ & $\begin{array}{l}\text { (Desai et al., 2014; Hu } \\
\text { et al., 2002) }\end{array}$ \\
\hline Catalase & Antioxidant enzyme & $\begin{array}{l}\text { Peroxisome } \\
\text { matrix, cytosol }\end{array}$ & $\begin{array}{l}\text { Hijacked to nucleus by plant pathogens to } \\
\text { modulate cell death but mechanism unknown }\end{array}$ & (Zhang et al., 2015) \\
\hline MSH1 & $\begin{array}{l}\text { Required for organelle } \\
\text { genome stability }\end{array}$ & $\begin{array}{l}\text { Plastid and } \\
\text { mitochondrial } \\
\text { targeted }\end{array}$ & Alteration in nuclear DNA methylation & (Virdi et al., 2015) \\
\hline pdNAD-MDH & $\begin{array}{l}\text { NAD-dependent } \\
\text { malate } \\
\text { dehydrogenase }\end{array}$ & Plastid & $\begin{array}{l}\text { Activity independent stabilisation of Fts } \mathrm{H} 12 \\
\text { component of inner envelope membrane protease } \\
\text { AAA-ATPase complex. Essential for viability }\end{array}$ & (Schreier et al., 2018) \\
\hline $\begin{array}{l}\text { AROGENATE } \\
\text { DEHYDRATASE2/5 }\end{array}$ & $\begin{array}{l}\text { Phenyl alanine } \\
\text { Biosynthesis }\end{array}$ & $\begin{array}{l}\text { Stroma and } \\
\text { stromules }\end{array}$ & $\begin{array}{l}\text { Interaction with chloroplast division machinery. } \\
\text { ADT5 isoform located in nucleus }\end{array}$ & (Bross et al., 2017) \\
\hline GAPDH isoforms & $\begin{array}{l}\text { Glycolysis } \\
\text { Calvin cycle }\end{array}$ & cytosol & $\begin{array}{l}\text { Redox sensitive protein accumulating in the } \\
\text { nucleus under stress conditions }\end{array}$ & $\begin{array}{l}\text { (Zaffagnini et al., } \\
\text { 2013) (Yang and Zhai, } \\
\text { 2017). }\end{array}$ \\
\hline LSD1 & $\begin{array}{l}\text { Forms redox } \\
\text { dependent interaction } \\
\text { with a suite of proteins } \\
\text { affecting cell division } \\
\text { vs cell death }\end{array}$ & $\begin{array}{l}\text { Cytosol } \\
\text { nucleus }\end{array}$ & Transcriptional activator & $\begin{array}{l}\text { (Czarnocka et al., } \\
2017)\end{array}$ \\
\hline ACO1, aconitase & $\begin{array}{l}\text { Citrate metabolism, } \\
\text { mRNA binding }\end{array}$ & Cytosol & $\begin{array}{l}\text { TCA cycle enzyme and mRNA binding protein to } \\
\text { promote translation of CSD2 }\end{array}$ & (Moeder et al., 2007) \\
\hline
\end{tabular}


Protein export 1. Cleavage of membrane bound TF

e.g PTM1, ANAC013, ANAC017

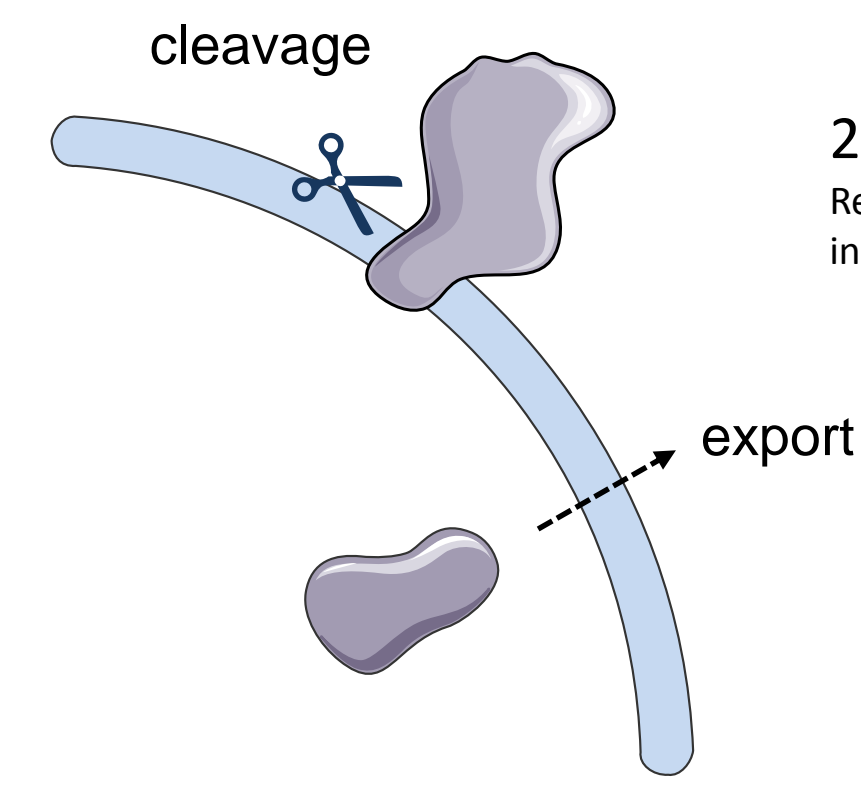

2. Export of proteins by UPS system akin to ERAD

Reported for all organelles. Linked to degradation of

individual proteins and also organelle quality control.

3. Transport via organelle contact sites?

Modifying protein import

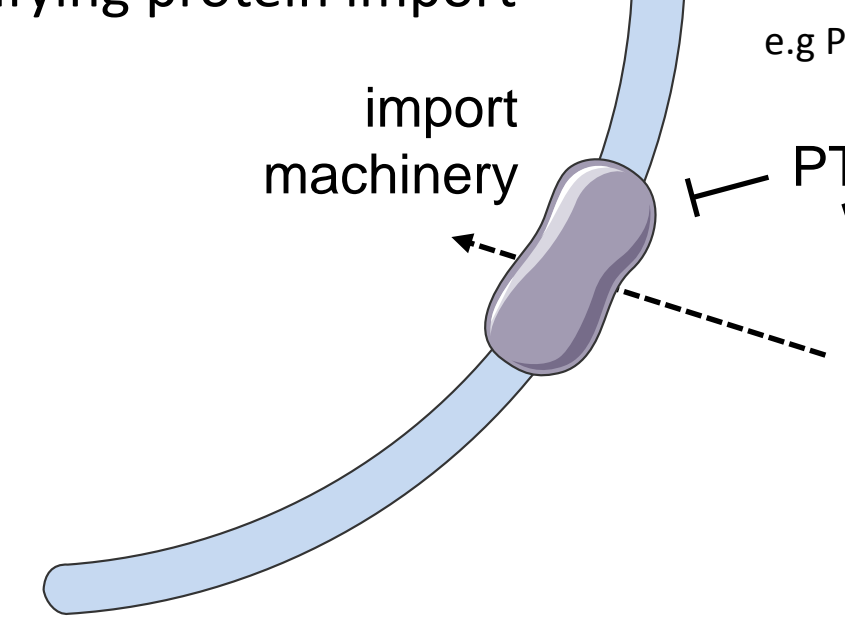

1. Modification of import machinery to slow/halt import

e.g Phosphorylation, Ub, redox modification.

2. Modification of precursor to prevent import

Interaction with cytosolic binding partners, modification of targeting signal

Figure 1. Potential mechanisms of protein relocation 


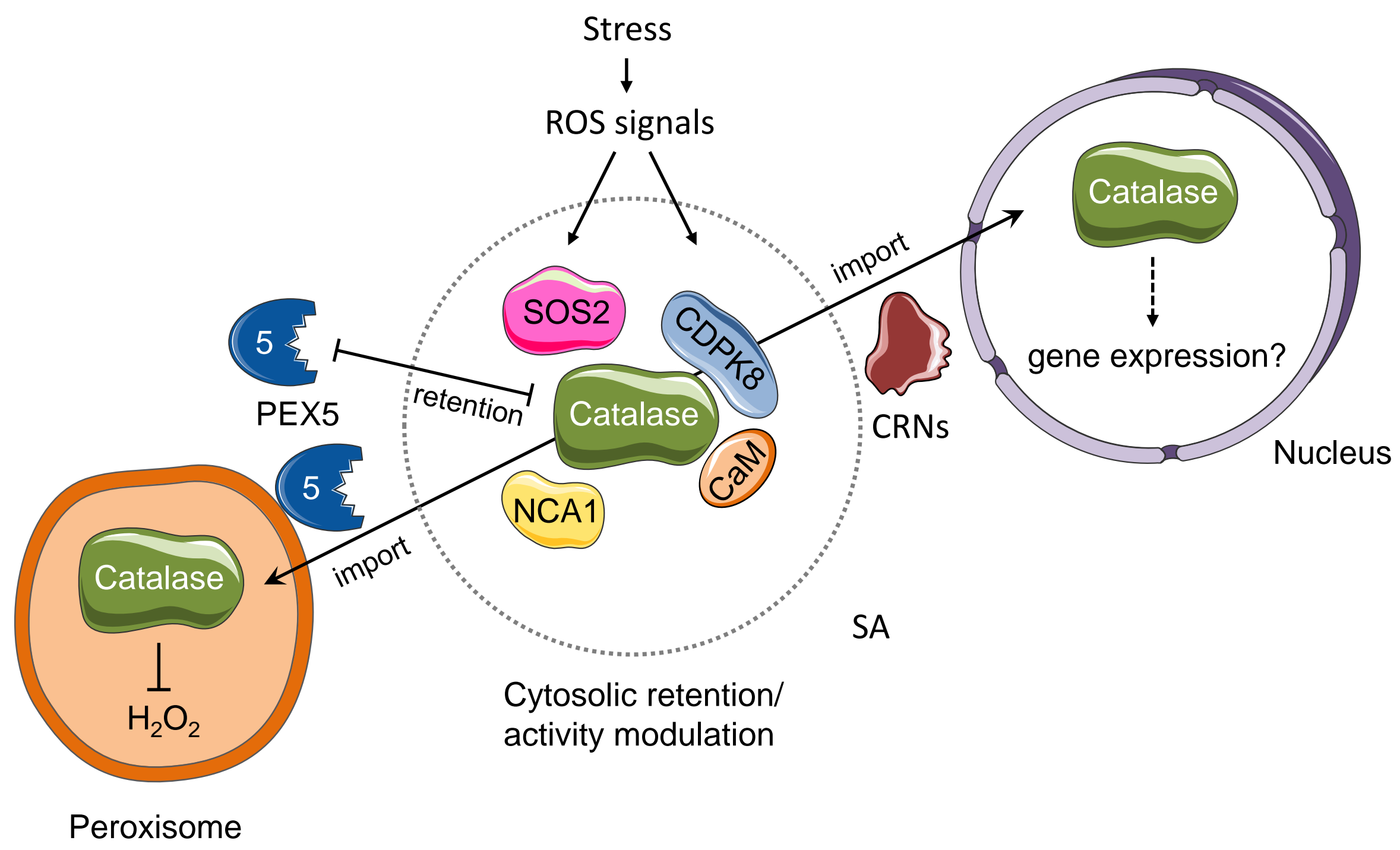

Figure 2. Switching partners: model for regulation of catalase localisation through interaction with different binding proteins. 


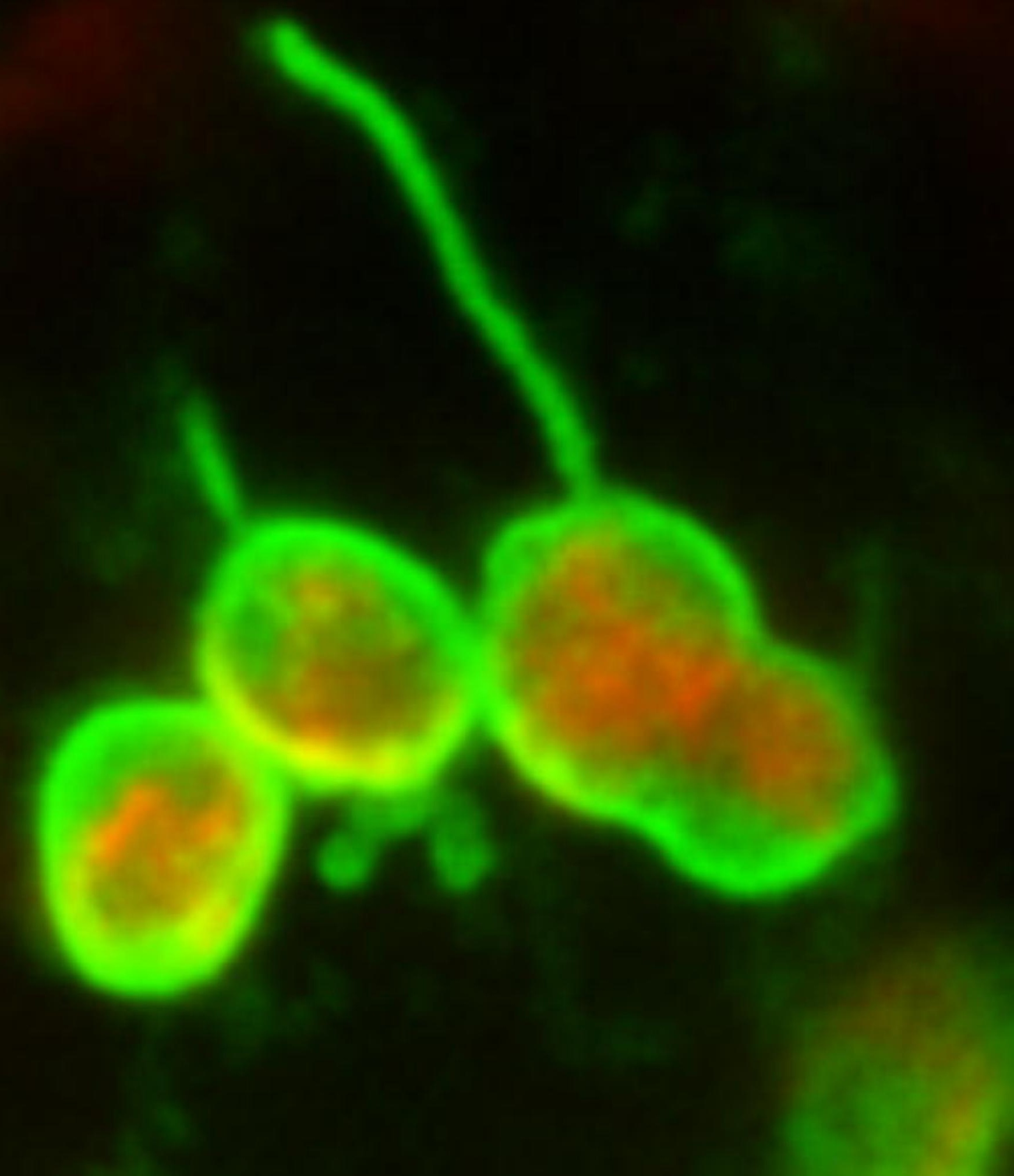




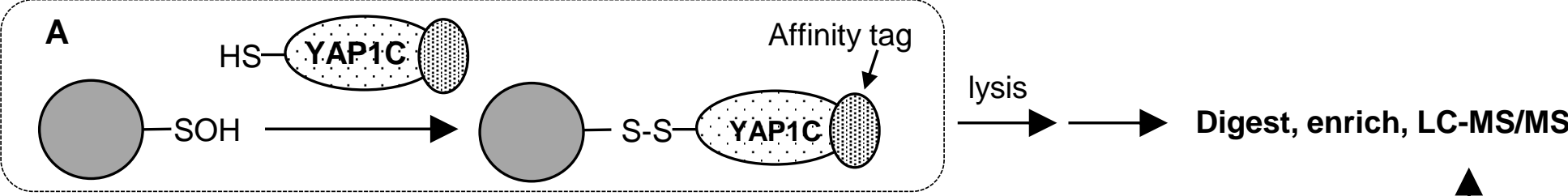

live cell labelling

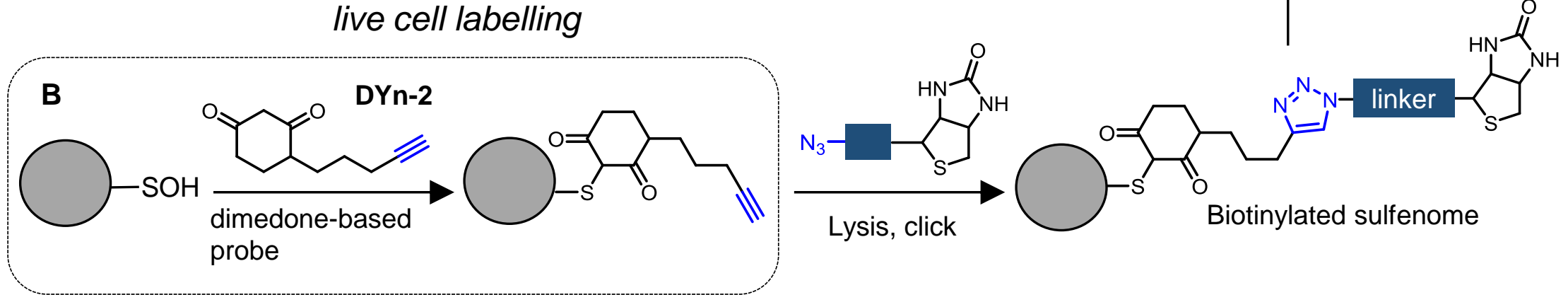

